\title{
Measuring Breadth and Depth of Vocabulary Knowledge of Chinese EFL Learners at Different Learning Stages
}

\author{
Liu Juan*, Li Xiang \\ Department of English, Guangdong Police College, Guangzhou, China \\ Email address: \\ 263614979@qq.com (Liu Juan) \\ ${ }^{*}$ Corresponding author \\ To cite this article: \\ Liu Juan, Li Xiang. Measuring Breadth and Depth of Vocabulary Knowledge of Chinese EFL Learners at Different Learning Stages. \\ International Journal of Language and Linguistics. Vol. 7, No. 4, 2019, pp. 166-171. doi: 10.11648/j.ij11.20190704.14
}

Received: May 23, 2019; Accepted: June 29, 2019; Published: July 22, 2019

\begin{abstract}
An updated Vocabulary Levels Test and an updated Word Associates Test are conducted to measure the breadth and depth of vocabulary Knowledge of Chinese EFL learners from junior middle school to senior middle school to college respectively in this research. The ANOVA analyses of the test results show that Chinese learners' breadth knowledge at any learning stage is insufficient and does not meet the requirements of corresponding English teaching syllabus although there is significant development from junior middle school to senior middle school to college. With the rise of learning stages, the difference of the acquisition of lower level words gradually disappears and the difference of higher level words appears. Compared to breadth knowledge, Chinese learners perform worse in the test of depth of vocabulary knowledge. Although there is a significant rise from lower stages to higher stages, the development of depth of vocabulary knowledge is very slow and dissatisfied. The main reason for it is that Chinese students value the expansion of vocabulary size and neglect the establishment of semantic and collocational relationship among words. The results of the Pearson correlation analysis show that there is little correlation between Chinese learners' breadth of vocabulary knowledge and depth of vocabulary knowledge.
\end{abstract}

Keywords: Breadth of Vocabulary Knowledge, Depth of Vocabulary Knowledge, Correlation, Chinese Learners

\section{Introduction}

Since vocabulary is the basis of any language, vocabulary learning have always been the focus of second language acquisition. Although Linguists and researchers have made lots of researches and yielded great achievements on vocabulary acquisition, the researches around vocabulary knowledge are still at the burgeoning stage. Generally, vocabulary Knowledge is categorized into two dimensions: breadth knowledge and depth knowledge [1]. Breadth of vocabulary knowledge is referred to how many words a learner knows at a certain level of language proficiency while depth of vocabulary knowledge is defined as a learner's knowledge of various aspects of a given word. In the previous researches, two methods are mainly adopted to measure L2 learners' vocabulary knowledge. One is to adopt vocabulary tests such as Vocabulary Levels Test, Vocabulary Size Test, Productive Levels Test and Vocabulary Knowledge Scale to evaluate learners' breadth and depth knowledge, the other is to measure vocabulary knowledge by analyzing learners' output such as writing, speaking and translation. As for breadth knowledge, there is little controversy on its concept and the tests on vocabulary size have been gradually improved on the basis of Vocabulary Levels Test (VLT) [2]. As for depth knowledge, however, there is no definition accepted by all linguists; therefore, the evaluations on depth knowledge are diverse. But without doubt, all researchers, on one hand, agree that vocabulary knowledge is central to second language acquisition and communicative competence development and plays a vital role in all language skills (i.e. listening, speaking, reading, and writing) [1, 3], on the other hand, the evaluation on breadth knowledge refers to the calculation of the total words a learner knows, which is useful for comparative studies between different groups, cross-sectional studies of a certain learning level or longitudinal studies.

Since the late 1990s, the researches concerning vocabulary Knowledge in L2 acquisition have shifted from breadth to depth [4]. The researches on depth knowledge can be roughly summarized into the following types: researches on definition of depth of vocabulary knowledge, researches on how depth of 
vocabulary knowledge is required, and the influences of depth of vocabulary knowledge on reading, speaking, translating performance [5]. In China, most relevant researches mainly focus on the influences of the development of Chinese Learners' depth knowledge on reading, writing and comprehensive proficiency and the relationship of depth and breadth knowledge $[4,6,7]$; several studies probe into the longitudinal development of learners' depth of vocabulary knowledge [8, 9]. In addition, He [10] and Tang [11] conducted researches on depth of vocabulary knowledge of English textbooks, which opens a new perspective in this field. However, up to now few empirical researches have been conducted to investigate the longitudinal development of Chinese English learners' vocabulary knowledge based on vocabulary tests. This study is to make a research on the longitudinal development of Chinese learners' vocabulary knowledge from junior middle school to college period based on tests of Vocabulary Levels Test and Word Associates Test. To achieve the objectives of the study, the following research questions are addressed:

1) How does breadth knowledge develop from junior middle school to college?

2) How does depth knowledge develop from junior middle school to college?

3) What is the correlation of breadth and depth knowledge during the development process?

\section{Measuring Breadth Knowledge}

\subsection{Participants}

The participants in the present study were 354 students from junior middle school (176 from Grade 8; 178 from Grade 9), 348 from senior middle school (175 from Grade 11 and 173 from Grade 12) ${ }^{1}$ and 327 college students (167 freshmen; 160 sophomores) in South China's Guangzhou city. The sample consisted of both male and female students and their English proficiency is at medium level among the students of the same learning period because they are from common middle school and university.

\subsection{Vocabulary Test}

The Updated Vocabulary Levels Test [12] and the University Level of the Vocabulary Levels Test [2] are combined into one for measuring breadth knowledge of Chinese learners at different learning stages in this research. Although both the Updated Vocabulary Levels Test and the University Level use a form-recognition matching format with each cluster containing three stems and six clusters to assess the breadth knowledge of learners at six levels: 1000, 2000, $3000,4000,5000$, the former indeed includes 10 clusters at each level and the latter only includes 6 clusters. Therefore, the total matching questions of the whole vocabulary test are 168.

\subsection{Results}

Table 1. ANOVA results of the total breadth knowledge of students at different learning Stages.

\begin{tabular}{llllll}
\hline & Sum of Squares & df & Mean Square & F & Sig. \\
\hline Between Groups & 466245.827 & 5 & 93249.165 & 191.707 & .000 \\
Within Groups & 497603.353 & 1023 & 486.416 & & \\
Total & 963849.180 & 1028 & & & \\
\hline
\end{tabular}

The results of the ANOVA in Table 1 reveal that the mean differences between the performance of the six group students on the test are large and significant. Table 2 shows that the mean scores is steadily rising from Grade 8 to sophomore. Therefore, it may be safely concluded that learners' breadth of vocabulary knowledge is on the rise with the promotion of learning levels.

Table 2. Means of breadth knowledge of different students.

\begin{tabular}{lllll}
\hline & Mean & N & Std. Deviation \\
\hline Grade 8 & 47.27 & 176 & 20.378 & PCT (total 168) \\
Grade 9 & 62.29 & 178 & 17.617 & $28 \%$ \\
Grade 11 & 83.15 & 175 & 24.211 & $37 \%$ \\
Grade 12 & 90.70 & 173 & 18.066 & $49 \%$ \\
Freshmen & 100.92 & 167 & 27.504 & $54 \%$ \\
Sophomore & 108.45 & 160 & 23.296 & $60 \%$ \\
\hline
\end{tabular}

Table 3. Multiple comparison of 1000 level words among different students (LSD).

\begin{tabular}{|c|c|c|c|c|c|c|}
\hline \multirow{2}{*}{ students } & \multirow{2}{*}{ students } & \multirow{2}{*}{ Mean Difference } & \multirow{2}{*}{ Std. Error } & \multirow{2}{*}{ Sig. } & \multicolumn{2}{|c|}{ 95\% Confidence Interval } \\
\hline & & & & & Lower Bound & Upper Bound \\
\hline \multirow{5}{*}{ Grade 8} & Grade 9 & $-4.392^{*}$ & .469 & .000 & -5.31 & -3.47 \\
\hline & Grade 11 & $-8.264^{*}$ & .471 & .000 & -9.19 & -7.34 \\
\hline & Grade 12 & $-8.812^{*}$ & .472 & .000 & -9.74 & -7.89 \\
\hline & Freshmen & $-8.833^{*}$ & .476 & .000 & -9.77 & -7.90 \\
\hline & Sophomore & $-9.769^{*}$ & .482 & .000 & -10.71 & -8.82 \\
\hline \multirow{4}{*}{ Grade 9} & Grade 11 & $-3.872^{*}$ & .469 & .000 & -4.79 & -2.95 \\
\hline & Grade 12 & $-4.420^{*}$ & .471 & .000 & -5.34 & -3.50 \\
\hline & Freshmen & $-4.442^{*}$ & .475 & .000 & -5.37 & -3.51 \\
\hline & Sophomore & $-5.378^{*}$ & .480 & .000 & -6.32 & -4.43 \\
\hline
\end{tabular}




\begin{tabular}{lllllll}
\hline \multirow{2}{*}{ students } & \multirow{2}{*}{ students } & \multirow{2}{*}{ Mean Difference } & \multirow{2}{*}{ Std. Error } & \multirow{2}{*}{ Sig. } & \multicolumn{2}{l}{ 95\% Confidence Interval } \\
\cline { 6 - 7 } Grade 11 & Grade 12 & -.548 & .473 & .247 & -1.48 & Lower Bound \\
& Freshmen & -.570 & .477 & .233 & -1.51 & .38 \\
& Sophomore & $-1.506^{*}$ & .482 & .002 & -2.45 & .37 \\
Grade 12 & Freshmen & -.022 & .478 & .964 & -.96 & -.56 \\
Freshmen & Sophomore & $-.958^{*}$ & .484 & .048 & -1.91 & .92 \\
\hline
\end{tabular}

*. The mean difference is significant at the 0.05 level.

Table 4. Mean of breadth knowledge at different stages.

\begin{tabular}{|c|c|c|c|c|c|c|c|c|c|c|c|c|}
\hline & \multicolumn{2}{|c|}{1000 level } & \multicolumn{2}{|c|}{2000 level } & \multicolumn{2}{|c|}{3000 level } & \multicolumn{2}{|c|}{4000 level } & \multicolumn{2}{|c|}{5000 level } & \multicolumn{2}{|c|}{ University level } \\
\hline & mean & PCT & mean & PCT & mean & PCT & mean & PCT & mean & PCT & mean & PCT \\
\hline Grade 8 & 19.2 & $64 \%$ & 10.5 & $35 \%$ & 5.7 & $19 \%$ & 5.1 & $17 \%$ & 4.2 & $14 \%$ & 2.6 & $14 \%$ \\
\hline Grade 9 & 23.5 & $78 \%$ & 15.9 & $53 \%$ & 7.3 & $24 \%$ & 6.2 & $21 \%$ & 6.1 & $20 \%$ & 3.3 & $18 \%$ \\
\hline Grade 11 & 27.4 & $91 \%$ & 19.7 & $66 \%$ & 14.7 & $49 \%$ & 10.6 & $35 \%$ & 7.7 & $26 \%$ & 3.8 & $21 \%$ \\
\hline Grade 12 & 27.9 & $93 \%$ & 23.4 & $78 \%$ & 15.6 & $52 \%$ & 11.9 & $40 \%$ & 8.1 & $27 \%$ & 3.8 & $21 \%$ \\
\hline Freshmen & 28.0 & $93 \%$ & 24.1 & $80 \%$ & 19.9 & $66 \%$ & 14.3 & $48 \%$ & 11.0 & $37 \%$ & 5.0 & $28 \%$ \\
\hline Sophomore & 28.9 & $96 \%$ & 26.0 & $87 \%$ & 20.3 & $68 \%$ & 15.7 & $52 \%$ & 12.0 & $40 \%$ & 5.6 & $31 \%$ \\
\hline
\end{tabular}

Table 4 exhibits two types of information. On one hand, observation from left to right column shows that Chinese learners' breadth knowledge of different levels is decreasing with the promotion of learning stages. That is, the higher the learning stage is, the more vocabulary Chinese learners need to acquire, and the less width knowledge Chinese learners obtain. On the other hand, observation from top to bottom line shows that so far as vocabulary level is concerned, Chinese learners' breadth knowledge of each level is increasing with the promotion of learning stages.

An ANOVA analysis between groups demonstrates that the mean differences among the vocabulary sizes of Chinese learners of different stages at any vocabulary level are significant. However, multiple comparisons show that so far as any vocabulary level is concerned, the significance between two stages of students is not always significant. Concretely speaking, as for 2000 level, there is no significant difference between Grade 12 and Freshmen $(\mathrm{p}=0.299)$ although other comparisons between groups show significant difference. At 3000 level, there is no significant difference between Grade 11 and Grade $12(\mathrm{p}=0.112)$ as well as freshmen and sophomore ( $p=0.508$ ). At 4000 level, all comparisons between two groups show significant difference except the comparison between Grade 8 and Grade $9(\mathrm{p}=0.053)$. At 5000 level, the mean differences between two groups are significant except Grade 8 and Grade $9(\mathrm{p}=0.278)$ and Grade 11 and Grade $12(\mathrm{p}=0.426)$. At university vocabulary level there is no significant difference among Grade 9, Grade 11 and Grade 12, and between Freshmen and Sophomore although difference is significant between Grade 8 and all other students, and between Grade 11, Grade 12 and college students.

\section{Measuring Depth Knowledge}

\subsection{The Definition of Depth Knowledge}

Richards [13] stated that depth of vocabulary knowledge included relative frequency and collocation, limitations on use, syntactic behavior, basic forms and derivations, association with other words, semantic value. Nation proposed that lexical knowledge consisted of defined form, position, function, and meaning [2]. Qian refined the previous definition and proposed that depth of vocabulary knowledge included pronunciation, spelling, morphological properties, syntactic properties, meaning, register, and frequency. Based on the previous definition, this study takes three major dimensions of depth of vocabulary knowledge into consideration, namely, synonym, polysemy and collocation $[14,15]$.

\subsection{Method for Evaluating Depth Knowledge}

\subsubsection{The Updated Word Associates Test}

Read designed Word Associates Test (WAT) to measure the receptive aspect of depth of vocabulary knowledge based on the main relations of syntagmatic, paradigmatic, and analytic relationships [16]. The test is composed of 40 items each of which consists of one stimulus word, which is an adjective, and two boxes each containing four words. The left box shows the synonymous words and the right one shows the collocations of the stimulus word. Among the four words in the left box, one to three words can be synonymous to one aspect of, or the whole meaning of the stimulus word. Among the four words in the right box, there can be one to three words that collocate with the stimulus word. Although WAT is considered as an effective and credible method to measure depth of vocabulary knowledge, it is pitiful that only adjectives are included in this test. Therefore, many adapted versions have been designed and validated to test depth knowledge [14, 17-19]. However, undoubtedly, it was developed to measure three vocabulary elements: synonymy, polysemy, and collocation [20]. In this research, the author also revised WAT and designed an updated version by adding 10 stimulus words which include five verbs, four nouns and one adverb. All the added items are chosen from the word list of national English teaching syllabus for college English and middle school English. So totally there are 50 items and 200 correct answers in the updated word associates test. 


\subsubsection{Participants}

Before formally conducting the Updated Word Associates Test, a pilot study is made to evaluate the validity. The results show that the test is not valid for junior middle school students because most of the words used in this test are strange words for them and their scores are very low. Therefore, finally only senior middle school students and college students participate in the formal test, and the same students participating in the test of breadth knowledge are recruited as subjects in this test.

\subsection{Results}

As shown in Table 5, only sophomores acquire over half of the total score, which means that Chinese students' collocation and synonym knowledge is especially insufficient. The AVOVA analysis shows that there is significant difference between groups $(\mathrm{F}=25.59, \mathrm{P}=0.00)$, which means that the depth of vocabulary knowledge is on the rise with the promotion of learning stages.

Table 5. Means of the depth knowledge of different students.

\begin{tabular}{lllll}
\hline & Mean & N & Std. Deviation & PCT (total 200) \\
\hline Grade 11 & 83.83 & 175 & 33.98 & $42 \%$ \\
Grade 12 & 89.69 & 173 & 35.31 & $45 \%$ \\
Freshmen & 109.14 & 167 & 29.3 & $55 \%$ \\
Sophomore & 123.29 & 160 & 18.19 & $62 \%$ \\
\hline
\end{tabular}

Table 6. Multiple Comparisons of mean difference (LSD).

\begin{tabular}{|c|c|c|c|c|c|c|}
\hline \multirow{2}{*}{ students } & \multirow{2}{*}{ students } & \multirow{2}{*}{ Mean Difference } & \multirow{2}{*}{ Std. Error } & \multirow{2}{*}{ Sig. } & \multicolumn{2}{|c|}{ 95\% Confidence Interval } \\
\hline & & & & & Lower Bound & Upper Bound \\
\hline \multirow{3}{*}{ Grade 11} & Grade 12 & -5.858 & 4.813 & .224 & -15.33 & 3.61 \\
\hline & Freshmen & $-25.312^{*}$ & 4.762 & .000 & -34.68 & -15.95 \\
\hline & Sophomore & $-39.459^{*}$ & 4.737 & .000 & -48.78 & -30.14 \\
\hline \multirow{2}{*}{ Grade 12} & Freshmen & $-19.453^{*}$ & 4.704 & .000 & -28.70 & -10.20 \\
\hline & Sophomore & $-33.601^{*}$ & 4.679 & .000 & -42.80 & -24.40 \\
\hline Freshmen & Sophomore & $-14.147^{*}$ & 4.626 & .002 & -23.25 & -5.05 \\
\hline
\end{tabular}

*. The mean difference is significant at the 0.05 level.

The results of AVOVA multiple comparisons between groups are exhibited in Tale 6 . The results show that there are significant differences between two groups except Grade 11 and Grade 12, which means that from Grade 12 to freshmen to sophomore, Chinese students' depth knowledge increases significantly.

\section{The Correlation of Breadth and Depth Knowledge}

In order to investigate the correlation of depth of vocabulary knowledge and breadth of vocabulary knowledge, a Pearson correlation analysis is conducted and the results are shown in Table 7.

Table 7. Pearson correlation analysis.

\begin{tabular}{|c|c|c|c|c|c|c|c|c|}
\hline \multicolumn{9}{|l|}{ Depth knowledge } \\
\hline \multirow{3}{*}{ Breadth knowledge } & Grade 11 & & Grade 12 & & Freshmen & & Sophomo & \\
\hline & Pearson & Sig. & Pearson & Sig. & Pearson & Sig. & Pearson & Sig. \\
\hline & -0.16 & 0.15 & 0.05 & 0.63 & -.209 & 0.05 & 0.05 & 0.63 \\
\hline
\end{tabular}

*. The mean difference is significant at the 0.05 level.

As shown in Table 7, there is no correlation between depth of vocabulary knowledge and breadth of vocabulary knowledge for students at different learning stages except Freshmen. The result signifies generally that Chinese students pay more attention to the expansion of vocabulary size and neglect or ignore the connections of collocation and synonym among words.

\section{Discussion}

The National English Teaching Syllabus for junior middle school requires that Level one students should master at least 450 words, plus 100 phrases and collocations and Level two students should master 800 words plus 200 phrases and collocations as well as 400-500 recognized words. Table 4 shows that Grade 8 and Grade 9 students know approximately 640 words of 1000 level words (64\%) and 780 words of 1000 level words $(78 \%)$, which means that the breadth of vocabulary knowledge of Chinese junior middle school students does not meet the requirements of the teaching syllabus. The National English Teaching Syllabus for senior middle school requires that senior middle school graduates should master 3500 words. The results show that Grade 12 students know $93 \%$ of 1000 level words, $78 \%$ of 2000 level words, $52 \%$ of 3000 level words and $40 \%$ of 4000 level words. In other word, senior middle school students only recognize approximately 2630 most common words, which is far less than the required 3500 words. The National College English Curriculum Requirements suggest graded teaching and accordingly put forward three levels of requirements. The primary level requires that college students acquire 4795 words and 700 phrases with 2000 active words; the higher level 6295 words and 1200 phrases with 2200 active words; the highest level 7675 words and 1870 phrases with 2360 active words. As shown in Table 4, Sophomores recognize 
$96 \%$ of 1000 level words, $87 \%$ of 2000 level words, $68 \%$ of 3000 level words, $52 \%$ of 4000 level words, $40 \%$ of 5000 level words and $31 \%$ of university level words, that is, their total vocabulary size is around 3740 words, which is far less than 4795 words. It means that generally college students do not meet the basic requirements, let alone the higher and highest requirements. In addition, the higher the word level is, the less words Chinese students recognize. When it comes to the corresponding word level, senior school students and college students only know about half of the required words, which means that Chinese students do not reach the requirement of the specific learning stage.

The significant mean differences from Grade 8 students to sophomores demonstrate that Chinese students' breadth of vocabulary knowledge is on the rise; however, the extension of vocabulary size is not only from the acquisition of new words at higher word level, but also the acquisition of the lower level words. The multiple comparisons between groups at specific word level shows that with the development of learning stages, the difference of the acquisition of lower level words gradually disappears and the difference of higher level words appears.

As for Chinese learners' depth of vocabulary knowledge, students at all learning stages perform badly. Although there is a significant rise from lower stages to higher stages, the development is very slow and dissatisfied. The research results truly disclose the phenomenon or learning habit that Chinese students value the expansion of vocabulary size and neglect the establishment of semantic and collocational relationship among words. Moreover, it is the insufficient connections among students' recognized words that result in the uncorrelation between breadth and depth knowledge.

\section{Conclusion}

In this research, two tests were conducted to measure Chinese students' breadth of vocabulary knowledge, depth of vocabulary knowledge and correlation between them. The results show that generally Chinese students at different learning stages perform badly, especially in the aspect of depth of vocabulary knowledge. Chinese students' breadth knowledge at each stage does not meet the corresponding requirements and there is little correlation between breadth and depth knowledge. This research discloses that Chinese learners attach much importance to breadth knowledge and ignore the acquisition of depth knowledge, which sheds light on the reform of vocabulary learning and teaching, even textbook editing.

\section{Note}

1 Grade 11 and Grade 12 refers Grade 2 and Grade 3 of senior middle school respectively.

\section{Acknowledgements}

This research is funded by 2017 Guangdong Social Science Foundation Project (Foreign Language Subject) (GD17WXZ25) and 2018 Young Elite Teacher Training
Project of Guangdong Police College.

\section{References}

[1] Nation, P. (2001). Learning vocabulary in another language. Cambridge: Cambridge University Press.

[2] Nation, P. (1990). Teaching and Learning Vocabulary. New York: Newbury House Publishers.

[3] Schmitt, N. (2000). Vocabulary in language teaching. Cambridge: Cambridge University Press.

[4] Zhang, P. (2006). An Overview of Second Language Vocabulary Acquisition Research in China. Foreign Language and Their Teaching, 207, 21-26.

[5] Li, X. (2018). Exploring Chinese EFL Learners' Acquisition Development of Depth of Vocabulary Knowledge Based on Input Corpus and Output Corpus. Proceedings of the International Conference on Contemporary Education, Social Sciences and Ecological Studies. Atlantis Press, 494-499.

[6] Lv, CH. (2004). Vocabulary Size and its Influence on English Achievement as well as its Relationship to Depth of Lexical Knowledge. Foreign Language Teaching and Research, 2, 116-122.

[7] Li, X. (2017). Assessing the Roles of Breadth and Depth of Vocabulary Knowledge in Second Language Proficiency. Foreign Language Teaching and Research, 5, 352-359.

[8] Tan, XC. (2006). A Study of Chinese English Learners' Productive Vocabulary Development. Foreign Language Teaching and Research, 3, 202-207.

[9] Tan, XC (2007). A Study of English Learners' Development of In-depth Knowledge on Productive Vocabulary. Foreign Language Education, 3, 52-56.

[10] He, AP. (2015). On Vocabulary development in Streamlined EFL Course Books: A Perspective of Dynamic System Theory. Foreign Language Teaching and Research, 6, 898-908.

[11] Tang, JY. (2015). A Corpus-based Study on Depth of Vocabulary Knowledge in College English Textbooks. Higher Education Exploration, 1, 81-86.

[12] Webb, S., Sasao, Y., \& Ballance, O. (2017). The updated Vocabulary Levels Test: Developing and validating two new forms of the VLT. ITL - International Journal of Applied Linguistics, 168 (1), 34-70.

[13] Richards, J. C. (1976). The role of vocabulary teaching. TESOL Quarterly, 10, 77-89.

[14] Qian, D. D. (1998). Depth of vocabulary knowledge: assessing its role in adult's reading comprehension in English as a second language. Unpublished $\mathrm{PhD}$ Dissertation.

[15] Qian, D. D. (1999). Assessing the roles of depth and breadth of vocabulary knowledge in reading comprehension. The Canadian Modern Language Review, 56 (2), 282-307.

[16] Read, J. (1993). The development of a new measure of L2 vocabulary knowledge. Language Testing, 10 (3), 355-371.

[17] Ishii, T., \& Schmitt, N. (2009). Developing an integrated diagnostic test of vocabulary size and depth. RELC Journal, 40 (1), 5-22. 
[18] Laufer, B., Elder, C., Hill, K., \& Congdon, P. (2004). Size and strength: do we need both to measure vocabulary knowledge? Language Testing, 21 (2), 202-226.

[19] Schmitt, N., Ching Ng, J. W., \& Garras, J. (2011). The Word Associates Format: Validation evidence. Language Testing, 28 (1), 105-126.
[20] Qian, D. D. (2002). Investigating the relationship between vocabulary knowledge and academic reading performance: an assessment perspective. Language Learning, 52 (3), 513-536. 